\title{
The Research of Multinational Enterprises Transnational Management
}

\author{
Li Chong ${ }^{1, a}$ \\ ${ }^{1}$ Faculty of International Trade, Shanxi University of Finance and Economics, Wucheng Road, Taiyuan, China
}

\begin{abstract}
With the development of global business, MNEs are always sinking into various pressures which are related to economic factors, social factors and informational factors. This situation making MNEs' strategies is supposed to achieve those requirements that including global market integration, national responsiveness, worldwide learning. There are four important strategies which are widely used in MNEs internationalization process that including multinational strategy, global strategy, international strategy, and transnational strategy. This essay will introduce pursuing transnational strategy and some difficulties existing in this process. Furthermore, an example of an entrepreneurial subsidiary will be chosen to explore and conduct further research.
\end{abstract}

\section{INTRODUCTION}

Getting benefits from the development of global business, MNEs are becoming one of the most pervasive types of business organization. A multinational enterprise is one which controls assets, factories, mines, sales offices, and the like in two or more countries (UN, 1973). The difference between traditional definitions emphasized the ownership and control of assets, and modern MNEs pay more attention to a significant influence in this current business environment.

\section{TRANSNATIONAL STRATEGY PURSUING AND DIFFICULTIES}

There are significant distinctions among pursuing the global strategy, international strategy, multinational strategy, and transnational strategy. The global strategy focuses on improving effectiveness but lacking flexibility and learning capabilities. This strategy was widely used in Japanese MNEs such as Toyota, Canon, and Komatsu. They rely on this strategy to obtain a balance between production cost and products. The international strategy focuses on achieving technology innovation worldwide; however, it possesses challenges in learning them. Most of the foreign subsidiaries are becoming sale unit which helps parent company reduce excess inventory and elimination of obsolete products. Multinational strategy bases on national differences to improve their effective market behaviours. There are many European MNEs such as Philips and Nestle, following this strategy to operate internationally. However, most of those enterprises' assets and resources were a dispersion in the term of enterprises' growth. Their foreign subsidiaries enjoy high-level autonomy thus more difficult for the parent company to manage them. The modern transnational strategy is attempting to be simultaneously both globally coordinated and locally responsive. This strategy is not only emphasizing decentralized, interdependent, and specialized characteristics in MNEs' configuration of assets and capabilities but also transnational awareness. Compared with other traditional approaches, transnational knowledge makes transnational approach have individual advantages such as contact and coordination operations, maintain competitiveness and market effectiveness. Based on the economic benefits of the multinational firm, transnational strategy achieves various strategies and organizational structures that could be used to maximize the advantage relating to their subsidiaries in other countries' market.

Relating to the case, BD aims to design a localized international business with the purpose of helping everyone to maintain a healthy life. It attempts to inspire the employees around the globe that they are saving lives and making changes to medical practice and improving health care. Thus, it establishes a transnational strategy which met the demand for the local and global working relationship. This has increased collaborations and commitment between the organizational structure. Opening Research development plants abroad has raised the needs of the distinct markets providing the return.

To further illustrate the process of translational strategy, $P \& G$ another multinational company that made a global expansion. The benefits of pursuing transnational strategy are observed through the increased revenue as well as market share within its industry. Furthermore, through the global expansion, $P \& G$ were able to capture and leverage on the new consumer segment of the market. These positive effects have proven P\&G's capability in producing exceptional products.

a Bourne_li@163.com 
Through implementing the transnational strategy, Matsushita and Philips attempted to improve its income. The development of the export market and constant adaptation to the market through continuous changes in demand and organization has to be the two procedures carried out within their transnational strategy.

However, it is challenging to implement the transnational strategy for most of the MNEs. There is a great challenge related to organizational structure and administrative heritage and strategies' characteristic.

First of all, organizational structure and administrative heritage will be delicate for MNEs implement the transnational strategy. In the 1960s, Stopford created a "stages model" to describe MNEs' foreign expansion. Stopdford and Well's international structural and stages model indicate that there are three different stages in MNEs' the foreign market behaviors, which are international division, alternate paths of development, global matrix. However, this matrix will be proved difficult to operate in transnational strategy. Citibank had to give up this structure to build their organization. Beyond structure causing problems for MNEs' run their transnational strategy in foreign market. Furthermore, administrative heritage will also take negative influence in building organizational capability. MNEs' subsidiaries enjoy high-level anatomy. However, this flexible characteristic provides challenges for traditional management. Philips Company loses their control abilities for their subsidiaries proved this problem difficult to be addressed.

MNEs transnational strategy organizational structure also influenced by local financial structure. Different countries always keep the different local financial structure. Germany is famous for its bank-based financial system. It provides steady financial support for their local enterprises, especially for international enterprises.
Actually, this type of financial solution which relies on the bank to solve financial stock has some limitation in the term of enterprises' growth and mature. To improve the flexible of capital, there was some Germany company want to use the market-based finance method to take the place of the leading position of bank-based finance; however, it was difficult to be changed. It shows a strong dependence of local enterprises utilizing external funding for the regional financial system in the bank-based financial system. The United States is well known for its market-based economic system. Various financial solutions such as crowd investment, angel capital, and securitization provide strong financial support for American local small size enterprises. However, there are not very strong American small size enterprise expansion behaviours in the past few years. Manigart believes there is a more complex reason causing that. However, various investment choices will help the small-sized enterprise more comfortable environment to operate their business idea. Furthermore, NASDAQ also provides a convenient environment for local American SMEs to make equity finance. Different from those countries, Chinese is the bank-based financial system. Bank financing takes the place of dominate. However, in recent years, the increase of market-oriented investment show Chinese financing system starts to show market-oriented characteristics. The improvement of current policies and the reduction of barriers for enterprises improve Chinese environment for SMEs development. Getting benefits from the environment change, there are more and more Born Global Firms transfer their attention to the local market. Between 1998 and 2006, most of Chines MNEs were built in developed countries and put their products and value in the foreign target market. However, the current local financial structures changing raise the challenge for MNEs' barriers.

Table1. Aggregate Financing to the Real Economy (Flow)

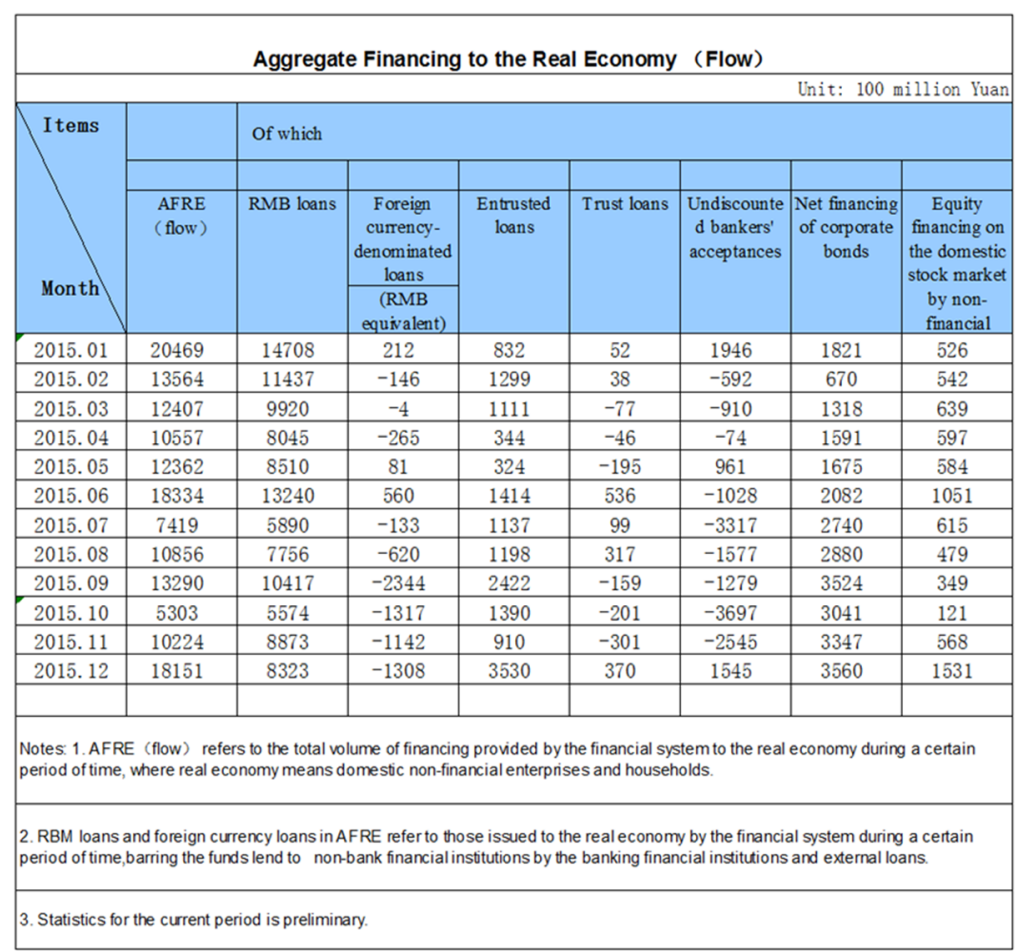

(source from: The people's Bank of China Statistics and Analysis Department, 2016) 


\section{Chinese Aggregate Financing to the Real Economy in}

2015

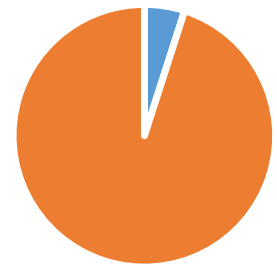

- Equity financing on the domestic stock market by non-financial enterprises

- Bank-based financing system services

(Source from: The people's Bank of China Statistics and Analysis Department, 2016)

Fig1. Chinese Aggregate Financing to the Real Economy in 2015

\section{The growth rate of Chinese equity financing on the domestic stock market by non-financial enterprises}

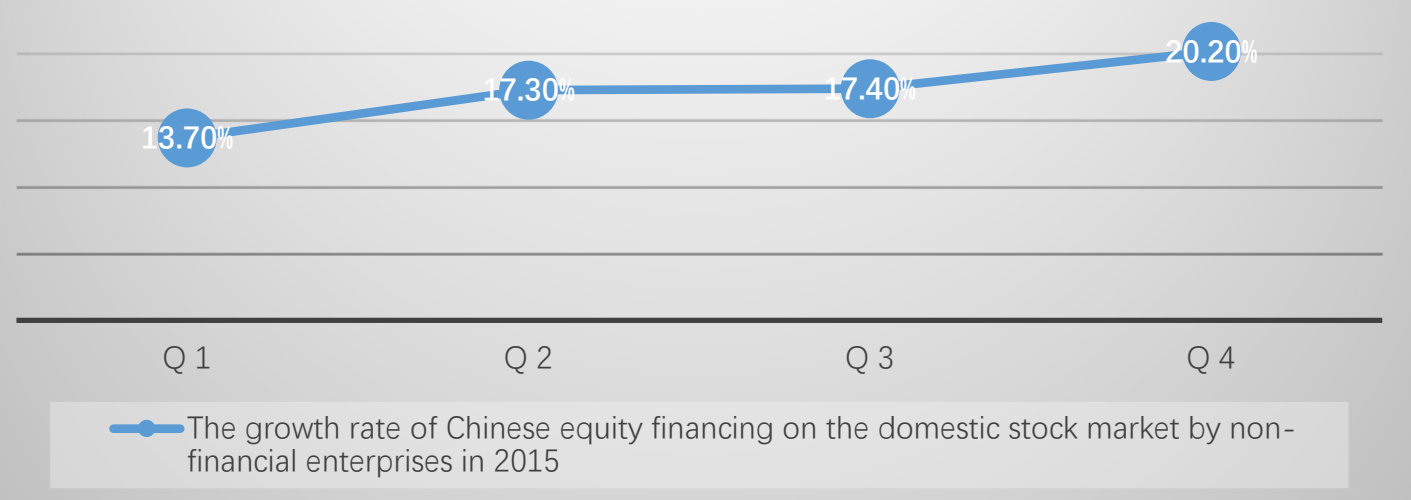

(Source from: The people's Bank of China Statistics and Analysis Department, 2016)

Fig2. The growth rate of Chinese equity financing on the domestic stock market by non-financial enterprises

The growth opportunities in the region could significantly influence the real growth of the born global firm as it could generate greater profit-generating activities available for the firm. Additionally, it also benefits from the growth of the currency of the underlying country. However, as the countries grow, the FDI policies could be designed to attract foreign investments such as born global firms to set up headquarters. Hence the growth of the national economy might be able to increase the growth rate of the born global firms.

Secondly, the transnational strategy's characteristic is another challenge to operate this strategy. There are three different parts in the transnational strategy that including distributed interdependent capabilities, flexible integrative process, and multidimensional managing perspectives. To achieve those characteristic together provide huge challenges to develop their organization in the foreign market. Distributed interdependent capabilities make MNEs create an integrated network. Different from the dispersion of the commonwealth, the commonwealth of coordination and centralized management, this network encourages a positive relationship between Parents Company and their subsidiaries. In the ideal environment, parent company's technology transfer and FDI will enhance their subsidiaries' competitiveness in the local market. Same as that, Parents Company can also rely on their subsidiaries' activities to improve their effective market behaviours. However, this idea achievement always turns to other negative sides with various factors' influences. For example, Nike company subsidiaries' development was treated as a challenge for its parent company. Furthermore, the flexible integrative process is another challenge because it is difficult to operate. This provides higher requests for MNEs' managements. Managers are supposed to master great qualities about identifying various relationships and choose adopted roles according to functions, industries, regions, and time. The managing process can also be adjusted by-products, local 
policies, and regional economy. Those MNEs which are following traditional management or old structure always feel hard in this part. To protect the confidential business, Coca-Cola company feel huge pressure to enter into some Asian countries, especially some government, let them show the formula for their soft drink. Coco Cola Company keeps low effective market behaviours because of that. Finally, the other challenge is multidimensional managing perspectives. Facing strategic diversification factor and volatile business environment, MNEs are supposed to develop their multidimensional managing perspectives. That including subsidiary management, global business management, and global functions management. It is difficult to achieve those requirements together and make the balance in the operating transnational strategies' process. The imbalance between B\&D companies and their subsidiary in different terms show that it is difficult to manage subsidiary and global business.

\section{ENTREPRENEURIAL SUBSIDIARY IN THOSE FOUR CASES}

It is a great possibility for a firm to operate its transnational strategy to have entrepreneurial subsidiaries. There is a strong link between transnational strategy and entrepreneurial. The transnational strategy is supposed to create an effective organization to reflect simultaneously both globally coordinated but also locally responsive. MNC subsidiaries possess their distinctive entrepreneurial competencies that can be captured through the following constructs: innovation, risk-taking, reactiveness, networking, learning and autonomy. In fact, the transnational strategy encourages more and more entrepreneurial subsidiaries appearing in the foreign market.

Becton Dickinson a manufacturing company, with operations worldwide, and built-in 1897. Before their subsidiary great achievement in the foreign market, their market and profit distribution's center were in America. However, this center started to transfer because their European subsidiary rose. The imbalance between Parents Company and European subsidiary created a lot of conflicts. This situation makes Becton Dickinson attempt to find an effective solution to address these issues. One of this solution is related to restructure the organization. The other solution helps create positive influence between the parent company and its subsidiaries. By the research of this B\&D Company, implementing transnational strategy improve subsidiaries' networking, learning and autonomy.

McKinsey \& Company is famous as a consulting company worldwide. It established by James McKinsey in 1926. After the 1960s, this company started quickly international expansion. However, in the year of 1970s' external and internal problems make their manager started to reconsider their fast expansion behaviours. Furthermore, it also shows they lack industry expertise. To address those issues, this company started to address the importance of innovation, risk-taking, and reactiveness when they implement their transnational strategy. Based on the development of McKinsey \& Company, implementing a transnational strategy can improve their subsidiaries' abilities about innovation, risk-taking, and reactiveness. This characteristic encourages entrepreneurial subsidiaries' capacities development.

Furthermore, Japanese P\&G Company's great achievement in the Asian market and Philips' subsidiaries enjoying autonomy show that enhancement of transnational strategy to their entrepreneurial subsidiaries. In sum, the overlapping between transnational strategy and entrepreneurial subsidiary encourages positive increase when MNEs operates its transnational strategy in the foreign market. With the developing of transnational strategy, the possible of entrepreneurial subsidiaries are also getting improvement.

\section{THE CHARACTERISTIC OF ENTREPRENEURIAL SUBSIDIARY}

Different other types, entrepreneurial subsidiary keeps individual characteristics. Traditional theory pointed out that the subsidiary is not only a provider of market entry but also a recipient of a parent company's technology transfer. Through organization simulation and technology learning, the subsidiary is becoming strategy development and implementation's positive participants. However, this theory is limited by the subsidiary's significant contribution (Gupta\&Govindarajan, 1994). By influenced of that, subsidiaries' innovation, autonomous behaviour, and entrepreneurial behaviours start to get more attention right now. Entrepreneurial subsidiary's characteristic can be justified as innovation, risk-taking, reactiveness, networking, learning and autonomy.

First of all, the entrepreneurial subsidiary's innovation, reactiveness, and risking taking address on the research and development work and effective market behaviours. In fact, subsidiary innovation is related to its tendency to espouse new and creative ideas, products, or processes in order to serve the host market (Lumpkin and Dess 1996). Research and development work for those enterprises is not only achieving to technology learning but also to achieve technology innovation. Furthermore, entrepreneurial subsidiary proactiveness is related to a perspective of advanced forward-looking about anticipating and acting on future market needs, thereby creating first-mover advantages (Miller 1983; Lumpkin and Dess 1996). Risk-taking is referring to involve the propensity to commit significant resources to exploit opportunities or operating a strategy or a business activity with highly uncertain outcomes in changing business environment (Miller 1983; Morris 1998; Keh et al. 2002). Mozilla Foundation is famous as a nonprofit organization around the world. In the year of 2005, the nonprofit Mozilla Foundation created a for-profit subsidiary, whose name is Mozilla Corporation. This subsidiary handles the explosive growth of the Firefox Web browser. Now, the for-profit makes about $\$ 104$ million a year from revenuesharing agreements with its search partners, including companies such as Google and Yahoo. Right now, Mozilla Corporation is focusing on the creation of internet of things that including Project Link, Project Sensor Web, Project Smart Home, and Project Vaani. This research and 
development achievement aims to provide multidimensional enjoyment for their customers. This project is an initial attempt to meet the future meeting of their target customers. However, considered the high-risk and uncertainty outcomes of the internet of things, the $\mathrm{R} \& \mathrm{D}$ is also treated as risk-taking behaviours.

Secondly, the other characteristic is networking. One of entrepreneurial subsidiary's innovation is creating effective networking in business communication. Based on this characteristic, the subsidiaries and parents company can achieve information share, technology share, and resource share. It is also referring to achieve effective teamwork in MNEs' network. Furthermore, entrepreneurial subsidiaries can also achieve resources transfer to other effective enterprise's produce function. The advance of networks creation of Mozilla Corporation is getting benefits from diversified collaboration. This advantage can easily to be proved by conflicts for Google in 2014. With the conflicts between Google and Mozilla Corporation, Mozilla Corporation achieves business development by collaboration with Yahoo and Baidu. Furthermore, this network also achieves resource transfer between Parents Company and subsidiary. Based on the running policies of Mozilla Foundation, Mozilla Foundation keeps absolute ownership of Mozilla Corporation. Mozilla Foundation will keep Mozilla trademarks and other effective assets related to intellectual property rights and authorize the use of power for Mozilla Corporation. Mozilla controls the source code database and auditing database.

Finally, the entrepreneurial subsidiary's characteristic can also be learning and autonomy. Learning is the address on the importance of global vision. Creating global innovation and learning is very important for those subsidiaries. Autonomy essentially refers to an independent action, which is not limited by organizational control and keep the power to develop a target market. Those characteristics can be proved by competitive aggressiveness. The competitive aggressiveness is related to an enterprises' excellent market effective behaviours aim to outperform their competitors in the current market (Lumpkin and Dess 1996). Those characteristics can be proved by the motivation of creating Mozilla Corporation and running policies between Mozilla Foundation and Mozilla Corporation. Mozilla Corporation is a whollyowned subsidiary of the Mozilla Foundation, which is a great nonprofit organization. Mozilla Corporation will not be taken over by other company or organization. They enjoy the high-level autonomy of research and development. Mozilla Corporation will focus on the development of Firefox and Thunderbird and monitoring product's promotion and funding. The total profits will put back to the Mozilla Foundation.

\section{EFFECTS OF ENTREPRENEURIAL SUBSIDIARY}

\subsection{ON INNOVATION OUTPUT}

Open inovation is a powerful framework encompassing the generation, capture, and employment of intellectual property at the firm level (West and Gallagher, 2006). Innovation is a key factor of entrepreneurial subsidiary's competitiveness. In the term of Mozilla Corporation's establishment and development, Mozilla Corporation shows great capabilities about innovation.

In the term of Mozilla Corporation's establishment, this entrepreneurial subsidiary was not becoming the parent company's technology recipients. Mozilla Corporation selective elimination some products that including Camino, Mariner, ElectricalFire, Xena, Mozilla Grendel, Minimo, Mozilla, Application Suite, Mozilla Sunbird, and Mozilla Calendar. However, they also make effective research and development to some valuable obsolete products. For example, Mozilla Corporation makes some research and development work in that. They use Gecko taking the place of Mariner. Furthermore, they use some Mozilla Sunbird's achievement to develop Lightning.

The innovation output is also referring to some new products' creation and new technology developing. The achievements of independent research and development belong to Mozilla Corporation are related to Sea Monkey, Mozilla Mail \& Newsgroups, Mozilla Composer, Chat Zilla, Mozilla Firefox, Mozilla Firefox Mobile, and Mozilla Thunderbird. Furthermore, Mozilla Corporation's research of development work which is related to the internet of things is treated an important threaten for Google Company's future market share developing.

Subsidiaries such as Mozilla corporation could also provide innovative output in the context of business operations improvement. Through employing and taking suggestions from the subsidiaries, the parent company could further optimize its business operations and in turn, increasing the innovative output. The effects of this innovative output could be seen by advances in business efficiencies and lower operating costs for the Mozilla.

In sum, the innovation output for Mozilla Corporation refers to old products' eliminate, obsolete products' development, and new products' innovation. In the process, Mozilla Corporation shows its excellent capabilities about innovation, risk-taking, and reactiveness.

\subsection{SUBSIDIARY PERFORMANCE}

In 2005, Mozilla Corporation was created by its parent company whose name is Mozilla Foundation. One of their business which is related to handle the explosive growth of the Firefox Web browser. Right now, the for-profit makes about \$104 million a year from revenue-sharing agreements with its search partners, including companies such as Google and Yahoo.

Last year, Mozilla Corporation announced its business plan refers to return donation for their open-source projects. This behaviour was treated as an unusual return behaviours in the internet industry. In the process, Continuous Build and Integration System Buildbot received \$ 15,000 funding. Read The Docs was got $\$ 48,000$. Discourse received over $\$ 25,000$. This return behaviour could provide improvement to its performance as it carries real corporate social responsibility. The 
observed increase in potentially all segments will likely follow, and a trend of growth in market share could be seen in the long run.

With the great development of Google business in recent years, Mozilla Corporation started to re-locate the relationship with Google Company. Actually, there is a close relationship between those companies. In 2005, there is $95 \%$ income of Mozilla Corporation coming from Google advertising revenue's share. The positive relationship was breaking up in 2014. Mozilla Corporation transfers its partnership to Yahoo. Right now, the adjusted developing strategies of Mozilla Corporation are treated as great targets for the Google future business plan.

\subsection{CONTRIBUTION TO LOCAL ECONOMY}

Mozilla Corporation is located in Mountain View, which is an important part of Silicon Valley. One of the main motivation of creating Mozilla Foundation is continuing the life of their predecessor, which is Netscape. In fact, there are a lot of staffs and managements in Mozilla Corporation who are working for Netscape before. For intense competition in Silicon Valley, Mozilla Corporation is reducing the unemployment rate and provide employment chances. Furthermore, it is also contributing in local government's tax.

The other contribution of Mozilla Corporation is technology spillovers. Actually, technology spillovers refer to foreign investment, cross-border trade and other related industries in the host country or enterprise's lifting effect about product development, production technology, management, marketing, and technology. The development of Mozilla Corporation is improving its competitors, such as Google's research and development work. Furthermore, Mozilla Corporation achieving technology share is improving their partnership company's competitiveness. Mozilla Corporation's innovation about the internet of things is stimulating this industry' development. In the end, Mozilla Corporation focuses on the development of professional staffs. With those staffs changing their work, they also improve other company's competitiveness. For example, before Christopher Blizzard taking a position of the lead developer in Facebook, he works in Mozilla Corporation and gets advanced education in three. Same as that, the other important professional staffs such as Mike Schroepfer and Mike Shaver also keep the same situation.

\section{CONCLUSION}

In conclusion, pursuing a transnational strategy in changing business environment can help enterprises' master many advantages. However, it is difficult to operate by influenced by organizational structure and administrative heritage and strategies' characteristic. Furthermore, entrepreneurial subsidiary's characteristic refers to innovation, risk-taking, reactiveness, networking, learning and autonomy. As it is most likely for a company implementing the transnational strategy to possess entrepreneurial subsidiaries based on the four cases discussed, the benefits of having them are shown in terms of innovative output and performance to the firm itself as well as in terms of economic development for the local economy.

\section{Acknowledgment}

This study supported by the project of the National Social Science Foundation Youth Project, "Export Trade of Chinese Service Industry and The Mechanism of Interactive Development in OFDI with its Productivity Effect" (Project Approval No.17CJY047) In 2017 was a phased achievement.

\section{References}

1. Buckley, P. J., \& Clegg, J. (Eds.). (2016). Multinational enterprises in less developed countries. Springer.

2. Bueno, N. (2017). Swiss multinational enterprises and transnational corruption: management matters. Swiss Review of Business Law, (2).

3. Collings, D. G., Mellahi, K., \& Cascio, W. F. (2019). Global talent management and performance in multinational enterprises: A multilevel perspective. Journal of management, 45(2), 540-566.

4. Goncalves, M., \& Cornelius Smith, E. (2017). Internationalization strategies of frontier LusophoneAfrican multinational enterprises: Comparative case studies of Angola and Mozambique. Journal Of Transnational Management, 22(3), 203-232. https://doi.org/10.1080/15475778.2017.1335127

5. Goncalves, M., \& Cornelius Smith, E. (2017). Internationalization strategies of frontier LusophoneAfrican multinational enterprises: Comparative case studies of Angola and Mozambique. Journal of Transnational Management, 22(3), 203-232.

6. Lee, I. H. I., Hong, E., \& Makino, S. (2020). The effect of non-conventional outbound foreign direct investment (FDI) on the domestic employment of multinational enterprises (MNEs). International Business Review, 101671.

7. Marano, V., \& Kostova, T. (2016). Unpacking the institutional complexity in adoption of CSR practices in multinational enterprises. Journal of Management Studies, 53(1), 28-54.

8. Mellahi, K., Frynas, J. G., \& Collings, D. G. (2016). Performance management practices within emerging market multinational enterprises: the case of Brazilian multinationals. The International Journal of Human Resource Management, 27(8), 876-905.

9. Mellahi, K., Frynas, J. G., \& Collings, D. G. (2016). Performance management practices within emerging market multinational enterprises: the case of Brazilian multinationals. The International Journal of Human Resource Management, 27(8), 876-905.

10. Shapiro, D., Hobdari, B., Oh, C. H., Kolk, A., \& Peng, M. (2018). Multinational enterprises and sustainable development in the extractive and natural resource 
sectors. Journal of World Business, 53(1), 1-14.

11. Yao, Y., \& Liu, L. (2019, September). Research on Corporate Governance of Multinational Enterprises. In 2019 International Conference on Advanced Education and Social Science Research (ICAESSR 2019). Atlantis Press. 